\title{
Defending the Wide-Scope Approach to Instrumental Reason
}

\author{
Jonathan Way \\ Forthcoming in Philosophical Studies.
}

\begin{abstract}
The Wide-Scope approach to instrumental reason holds that the requirement to intend the necessary means to your ends should be understood as a requirement to either intend the means, or else not intend the end. In this paper I explain and defend a neglected version of this approach. I argue that three serious objections to the Wide-Scope approach turn on a certain assumption about the nature of the reasons that ground the Wide-Scope requirement. The version of the Wide-Scope approach defended here allows us to reject this assumption, and so defuse the objections.
\end{abstract}

It is widely agreed that an account of practical rationality must include an instrumental principle - a requirement to intend what you believe to be the necessary means to your intended ends. The idea can be motivated by thinking about some simple cases. Suppose that you are at the fair, intend to ride the rollercoaster and believe that in order to ride you must stand in line. If you nonetheless do not intend to stand in line, something has gone wrong. You are irrational in a particularly clear and striking way: you fail to intend the believed necessary means to an intended end.

Notice that nothing was said about the reasons there are to ride the rollercoaster, or even the reasons you think there are. It might be, for instance, that you ought not to be at the fair at all, and so ought not to be riding the rollercoaster, or standing in line. Nevertheless, given your intention to ride, you would be irrational not to intend to stand in line. So to account for this kind of irrationality we seem to need a principle or requirement which is independent of the reasons you may have for the end - since there may not be any such reasons. That is why we need an instrumental principle. 
To this point most philosophers who have thought about this kind of case would agree. But they disagree widely over just how the instrumental principle is to be understood. According to what I will call the standard Wide-Scope account, the principle is to be understood along the following lines:

(WS) You ought to [intend to do M, if you intend to do $\mathrm{E}$ and believe that doing $\mathrm{M}$ is necessary for doing $\mathrm{E}]^{1}{ }^{1}$

In WS 'you ought' takes wide-scope, over the entire conditional within the brackets. The conditional is material, so WS is violated only when you intend an end, believe that a means is necessary for it, but do not intend this means. WS requires that you do not have this combination of attitudes. ${ }^{2}$ As I will sometimes say, it requires that you are not means-end incoherent.

WS avoids various difficulties that arise for other, perhaps prima facie more obvious, formulations of the instrumental principle. Consider the following 'narrowscope' principle:

$\left(\mathrm{NS}_{1}\right) \quad$ If you intend to do $\mathrm{E}$ and believe that doing $\mathrm{M}$ is necessary for doing $\mathrm{E}$, you ought to intend to do M.

\footnotetext{
1 'Along the following lines' because it is plausible that WS requires a little refinement. For example, the means action - doing $\mathrm{M}$ - must be one that you believe that you will do only if you intend to do it (Broome 2002: sec. 3). For simplicity, I will ignore this kind of complication in what follows.

${ }^{2}$ To save words I count not intending to do something as an attitude.
} 
$\mathrm{NS}_{1}$ has implausible consequences. For example, it implies that in the case described you ought to intend to stand in line. But this might not be the case. Perhaps you ought not to be at the fair at all, and so ought not intend to stand in line there.

This worry can be at least partially appeased by retreating to the following formulation:

$\left(\mathrm{NS}_{2}\right)$ If you intend to do $\mathrm{E}$ and believe that doing $\mathrm{M}$ is necessary for doing $\mathrm{E}$, you have a reason to intend to do $\mathrm{M}$.

$\mathrm{NS}_{2}$ implies only that you have a reason to intend to stand in line, and this is not nearly so implausible. Even if you ought to be elsewhere, you could still have some reason to ride the rollercoaster, and so some reason to intend to stand in line for it. However, $\mathrm{NS}_{2}$ does not explain what is wrong with means-end incoherence. That you have a reason to intend to stand in line does not imply that there is anything wrong with intending to ride without also intending to stand in line. There is nothing in general wrong with failing to intend as you have some reason to intend. There is only a problem in failing to intend against the weight of reasons. So $\mathrm{NS}_{2}$ does not capture the strictness of the instrumental principle - it does not capture the intuition that there is definitely something wrong if you intend an end but do not intend the necessary means to it. ${ }^{3}$ WS avoids both of these difficulties. As it does not imply that there is any particular attitude you ought to have, it does not have the implausible consequences of $\mathrm{NS}_{1}$. Even if you ought not to be at the fair, it could still be true that you ought to [intend

\footnotetext{
${ }^{3}$ For versions of both these objections to narrow-scope principles see Bratman 1987: 23-27 and Broome 1999: 409-10, amongst others.
} 
to stand in line, if you intend to ride the rollercoaster and believe that standing in line is necessary for riding]. And WS does imply that there is something wrong when you intend an end but do not intend the necessary means to it - it implies that you have a combination of attitudes you ought not to have. WS thus seems a promising account of your problem with the rollercoaster, and other cases of that structure. It gives us a strict norm which is violated, without obviously counter-intuitive implications.

WS has a further attraction. It is now common to distinguish between what you ought to do and what you are rationally required to do. What you ought to do depends on what you have reason to do, which is a matter of the (possibly unknown) facts of your situation. What rationality requires depends only on your attitudes concerning your situation. ${ }^{4}$ So it may seem that what you ought to do and what rationality requires can come apart. For example, it might be irrational not to intend to ride the rollercoaster, even though you ought not intend to ride. But drawing this distinction raises a question, and potential mystery, about how these apparently distinct types of requirement are related to each other. And WS allows a simple answer: the things you are rationally required to do are just some of the things you ought to do. As we might put it, rational requirements are wide-scope oughts ${ }^{5}$ - they are oughts which govern certain combinations of attitudes. Thus the appearance that oughts and rational requirements can come apart is deceptive. Your irrationality in not intending to stand in line is just your failing to do one of the things you ought to do - namely, [intend to stand in line, if you intend to ride the

\footnotetext{
${ }^{4}$ Sometimes the point is put by distinguishing between two senses of 'ought': sometimes the 'ought' of reasons and the 'ought' of rationality (Kolodny 2005: 509), sometimes the objective 'ought' and subjective 'ought' (Schroeder forthcoming). In this paper I try to use 'ought' only for what you have conclusive reason to do.

${ }^{5}$ I follow the now common practice of also using 'ought' as a noun, by analogy with 'reason'. An ought is what you have when you ought to do something.
} 
rollercoaster and believe that standing in line is necessary for riding]. There is thus no need to postulate two distinct normative relations: the ought relation and the rational requirement relation. The latter is subsumed under the former.

For the reasons just sketched, many writers have been attracted to the standard Wide-Scope account. Versions of it have been defended by John Broome, Jonathan Dancy, Stephen Darwall and R. Jay Wallace, amongst others. ${ }^{6}$ But it has come under increasing fire in recent years. Niko Kolodny, Joseph Raz, Andrew Reisner, Mark Schroeder and Kieran Setiya have all offered forceful objections to it. ${ }^{7}$ In this paper I discuss three of these objections. Each turns, in its own way, on the point just made: that WS is a claim about what you ought to do. I concede that these objections show this claim to be unsustainable. What you are rationally required to do need not be something you ought to do. The standard Wide-Scope approach thus fails. But this concession does not by itself undermine what I take to be the guiding idea of the Wide-Scope approach. The guiding idea is that the instrumental principle is a constraint on certain combinations of attitudes - on intending the end but not intending the means. This simple idea can be developed in ways that avoid commitment to WS and the identification of rational requirements with oughts. In this paper I develop and defend such a view. For reasons which will become clear, I call this the Wide-Scope Reasons view.

Although the Wide-Scope Reasons view does not identify rational requirements with oughts, it does not simply postulate distinct types of requirement. The view is embedded within a broader framework in which rational requirements are explained in terms of reasons. Very roughly, the framework says that the attitudes you are rationally

\footnotetext{
${ }^{6}$ Broome 1999, 2001, 2002, 2004, 2005; Dancy 2000; Darwall 1983, 2001; Wallace 2001.

${ }^{7}$ Kolodny 2005, 2007, 2008; Raz 2005; Reisner unpublished; Schroeder 2004, 2005, forthcoming; Setiya 2007b.
} 
required to have are those which, relative to your beliefs, you ought to have.

Consequently, it allows that there are many cases in which you ought to have the attitudes you are rationally required to have. It thus remains subject to versions of the three objections. However I argue that the view has the resources to answer these objections. My case for this depends on two claims. First, the objections each require a certain assumption about the nature of the reasons to comply with the instrumental principle. In terminology to be explained presently, they assume that the reason is state-given rather than object-given. Second, on the view defended here the reason to comply with the instrumental principle is object-given. If so, then the view is not susceptible to these objections. The paper thus amounts to a defense of the Wide-Scope approach to instrumental reason.

I will proceed as follows. In section 1, I introduce the influential Normativity Problem: the challenge of saying what reasons there are to comply with the instrumental principle. I argue that previous discussions presume that the reason must be state-given, and give a couple of reasons why we should instead expect the reason to be object-given. In section 2, I explain the Wide-Scope Reasons view and argue that it allows the reason to be object-given. In sections 3, 4 and 5, I show that this move allows us to escape two further problems - the Transmission Problem and the Evil Demon Problem. In section 5, I consider an objection to my proposal.

\section{The Normativity Problem}


The first objection to be considered is deceptively simple. WS is a claim about what you ought to do. And claims about what you ought to do are, or entail, claims about what you have conclusive reason to do. Thus WS entails that there is conclusive reason for you to [intend to do $\mathrm{M}$, if you intend to do $\mathrm{E}$ and believe that doing $\mathrm{M}$ is necessary for doing $\mathrm{E}$ ]. However there is conclusive reason for you to do something only if there is a reason for you to do that thing. And there is a reason for you to do something only if something is your reason to do it. So if you ought to comply with WS, something must be a reason for you to do so. But it is unclear what this reason is - it is unclear why you ought to comply with WS. This is the Normativity Problem.

Niko Kolodny has done most to develop this problem. ${ }^{8}$ He considers two answers to the question, 'why satisfy WS?' and argues convincingly that neither is satisfactory. I will briefly review these arguments.

First answer The reason to satisfy WS is that doing so has instrumental value. Satisfying WS will lead you to achieve other things you ought to achieve.

The first answer admits of weak and strong readings, depending on how we understand its second claim. On the strong reading, whenever you satisfy WS you will also achieve something else you ought to achieve. On the weak reading, a disposition to satisfy WS will lead you, over the long run, to achieve more of what you ought to achieve than you otherwise would (Broome 2005: 332-4).

\footnotetext{
${ }^{8}$ Kolodny 2005: 542-7, 2007: 238-41, 2008. See also Broome 2005: 334-5. Note that Kolodny typically offers these arguments as part of a general case against the idea that we have reason to satisfy so-called 'rational requirements'. On the instrumental principle in particular, see 2008, sec. 6.
} 
Second answer The reason to satisfy WS is that doing so is constitutive of intention.

This answer also allows two readings, depending on how we understand the idea that satisfying WS is constitutive of intention. On the strong reading, satisfying WS is constitutive of intention in that it is not possible to violate WS. On the weak reading, it is the disposition to satisfy WS which is constitutive of intention. Any agent with an intention will be disposed to satisfy WS with respect to that intention.

Both answers face parallel problems. On the one hand the strong reading of each answer seems false. The first because there are cases in which you satisfy WS but do not thereby achieve anything else you ought to achieve: for example, when you intend to do M, even though you ought not intend to do $\mathrm{M}$. The second because violation of WS seems intuitively possible. ${ }^{9}$ On the other hand, neither weak reading supports WS. WS implies that in every case you have conclusive reason to [intend to do $\mathrm{M}$, if you intend to do $\mathrm{E}$ and believe that doing $\mathrm{M}$ is necessary for doing $\mathrm{E}]$. But on the weak readings, each answer offers, at most, a reason to be disposed to satisfy this conditional. And a reason to be disposed to comply with WS does not imply a reason to comply with WS in every case. There can be reason to have a disposition even if there is not reason to exercise it in every case. A fortiori, the weak readings do not establish that in every case there is conclusive reason to comply with WS. ${ }^{10}$

\footnotetext{
${ }^{9}$ This seems to be agreed by most participants to this debate and I simply assume it here. For a contrary view see Finlay (2008).

${ }^{10}$ I understand both answers as first-order normative claims about the reasons we have. So in rejecting the second answer I do not mean to rule out that there may be a form of explanation of WS which appeals to
} 
I agree with Kolodny that these are significant problems for these answers. ${ }^{11} \mathrm{I}$ want to make a further observation. Both answers offer putative reasons to satisfy WS which are, in recently popular terminology, state-given rather than object-given. As it is ordinarily presented, this is a distinction between two kinds of reasons for attitudes. A reason for an attitude is object-given if it depends, in the appropriate way, on properties of the object of that attitude. A reason is state-given if it depends, in the appropriate way, on properties of the attitude - typically, on benefits of having the attitude. Perhaps the best known instance of this distinction is the distinction between pragmatic and epistemic reasons for belief. Pragmatic reasons to believe that $p$ are state-given reasons to believe that $p$. They are ways in which it would be good or beneficial to have the belief that $p$. Epistemic reasons are object-given reasons to believe that $p$. They are evidence that $p-$ the object of belief - is true. But the distinction can also be drawn for many other attitudes. For intentions, it is vividly illustrated by Gregory Kavka’s toxin puzzle (Kavka 1983). A million dollar prize for intending to drink an unpleasant toxin makes it beneficial to intend to drink the toxin, but not because of properties of drinking the toxin. It thus offers a pragmatic or state-given reason to intend to drink the toxin. In contrast,

constitutive norms of intention. For example, suppose that $p$ is the reason to comply with WS. This may in turn call for explanation - we can ask, 'why is $p$ a reason to comply with WS?' And the answer to this second-order question may, for all that has been said here, be that it is a constitutive fact about intention that $p$ is a reason to comply with WS. The argument only rules out that the first-order reason to comply (that $p$ ) is that doing so is constitutive of intention. For further relevant discussion see Kolodny 2005: 5446. I thank an anonymous referee for urging me to clarify this point.

${ }^{11}$ Kolodny also considers the suggestion that complying with principles like WS is simply worth doing in itself. He finds it 'outlandish that the kind of psychic tidiness that [WS] enjoins should be set alongside such final ends as pleasure, friendship and knowledge' (2007: 241). However even if we thought that there was something worthwhile about coherence, it is hard to see how this could be important enough to make sense of the strictness of instrumental reason. Compare Wedgwood 2003: 217. 
the fact that drinking the toxin will make you sick is an object-given reason against intending to drink it. ${ }^{12}$

The distinction between object- and state-given reasons is not typically applied to reasons for combinations of attitudes, like WS, but the extension is straightforward. A reason for a combination of attitudes is object-given if it depends, in the appropriate way, on properties of the objects of the relevant attitudes. It is state-given if it depends, in the appropriate way, on properties of the relevant combination of attitudes - typically, on benefits of having that combination of attitudes.

With this distinction in hand, we can see that both of the answers Kolodny considers offer putative state-given reasons to conform to WS. ${ }^{13}$ According to the first, the reason to comply with WS is that a certain pattern of attitudes would be instrumentally valuable. The idea is that the value of having that pattern of attitudes provides a reason to have them. According to the second, it is that this pattern of attitudes is constitutive of intention. If you are not at least disposed to satisfy WS, you are not an agent with intentions. Both answers thus appeal to properties of the recommended pattern of attitudes, not of the objects of those attitudes.

This should give us pause, for at least two reasons. First, many philosophers deny that there are state-given reasons for attitudes like belief and intention. For example, some philosophers think that the billionaire's offer is not a reason to intend to drink the toxin. They concede that the offer provides reason to want to intend to drink the toxin and

\footnotetext{
${ }^{12}$ My terminology follows Parfit 2001. The distinction is imprecise as it refers to an 'appropriate way' for reasons to depend on properties of the object or state. There is no consensus in the literature about how to state the distinction more precisely. For relevant discussion see Pink 1996; D’Arms and Jacobsen 2000; Parfit 2001; Rabinowicz and Rønnow-Rasmussen 2004; Stratton-Lake 2005; Hieronymi 2005; Olson and Daniellson 2007.

${ }^{13}$ Kolodny 2005: 551 claims that reasons to comply with WS would have to be state-given. I will argue that, whether or not this true about WS, it is not true of all Wide-Scope views.
} 
to try to cause yourself to intend to drink it. But they think that, strictly speaking, it provides no reason to intend to drink the toxin. ${ }^{14}$ The corresponding claim about reasons for belief is even more widely accepted. For example, many philosophers think that even if Pascal's wager establishes that believing in God has infinite utility, this does not, strictly speaking, provide reason to believe in God. Rather, it provides reason to want to believe in God, and to try to cause yourself to believe this. ${ }^{15}$ So a commitment to stategiven reasons is not a trivial one for Wide-Scopers.

Second, and more importantly, the instrumental principle is supposed to be the principle that underwrites our judgment that means-end incoherence is irrational. However if WS is grounded in state-given reasons, it is unclear that it can play this role. Even if we grant that there are state-given reasons, they are not central to judgments of rationality. It seems unfortunate, rather than irrational, that you are unable to intend to drink the toxin on the basis of the billionaire's offer. The point is clearer still with stategiven reasons for belief: it need not be irrational to believe something which there is great reward for believing. By contrast, object-given reasons do seem relevant to rationality. For instance, it is irrational to believe something when you are aware of compelling evidence against it. And it seems irrational to intend to drink the toxin, since you are aware of compelling reasons not to drink it (and so of compelling object-given reasons not to intend to do so).

If this is right then the two answers Kolodny considers are not good candidates to be the reason to comply with WS, even leaving aside the particular difficulties he finds with them. They could not ground the judgments of irrationality that the instrumental

\footnotetext{
${ }^{14}$ Pink 1996, Audi 2001: 257, n.7, Shah 2008, sec. 7.

15 There are even suggestions to this effect in Pascal (1996: 152). For a more recent example, see Shah 2006: 493-7.
} 
principle is supposed to explain. Still, it is unsurprising that these are the answers Kolodny considers, and which other writers have been tempted by. For it is very unclear what an object-given reason to comply with WS might be. WS is intended to apply in all circumstances. So an object-given reason to comply with it would have to be some feature of the objects of the attitudes it is concerned with - doing E, that doing $M$ is necessary for doing $\mathrm{E}$, and doing $\mathrm{M}$ - that hold in any circumstances whatsoever. It is very unclear what this feature might be. ${ }^{16}$

\section{Two Responses}

The Normativity Problem is thus a deep challenge to Wide-Scope accounts which accept WS. WS demands an object-given reason, but its universality makes it difficult to find one. But the problem is not fatal to the Wide-Scope approach as such. For not all WideScope accounts accept WS. As I put it above, the guiding idea of the Wide-Scope approach is that the instrumental principle constrains a certain combination of attitudes intending the end but not intending the means. And this idea can be developed in ways that do not involve WS. In this section, I consider two such ways. I begin by considering Broome's recent view that the instrumental principle is a claim about what rationality requires, not about what you ought to do. I will note a reason for dissatisfaction with this position. This will help to motivate my preferred version of the Wide-Scope approach, which will be defended in the rest of the paper.

Broome (2005) holds that:

\footnotetext{
${ }^{16}$ There is one obvious candidate: the entailment from the claims that you do $\mathrm{E}$ and that doing $\mathrm{M}$ is necessary for doing E to the claim that you do M (Broome 1999: 409). However there are well-known difficulties with the appeal to this entailment. See Wallace 2001: 18-20; Bratman forthcoming a, b.
} 
$\left(\mathrm{WS}_{\mathrm{RR}}\right) \quad$ You are rationally required to [intend to do $\mathrm{M}$, if you intend to do $\mathrm{E}$ and believe that doing $\mathrm{M}$ is necessary for doing $\mathrm{E}]$.

If this claim is to be distinct from WS, Broome must deny that the things you are rationally required to do are just some of the things you ought to do. He must think that the rational requirement relation is distinct from the ought relation. This allows him to deny that there must be reasons to comply with $\mathrm{WS}_{\mathrm{RR}}$, and thus evade the Normativity Problem. ${ }^{17}$

There is a broader picture motivating this move. On this picture, rationality is an "internal” matter, requiring the coherence of your non-factive mental states. Reasons are "external” - they are typically non-mental facts, of which you may be unaware. As such you need not be irrational in failing to respond even to conclusive reasons. The possibility is well illustrated by a famous example of Bernard Williams'. If your glass contain petrol but you believe it to contain gin, you may be rational to intend to take a sip although you have no reason to do so. ${ }^{18}$ And once we accept that reasons and rationality can come apart in this direction, it is hard to see the motivation for insisting that irrationality must nonetheless involve flouting reasons. We are thus led to a picture on which there is a distinction in kind between reasons (and thus oughts) and rationality.

\footnotetext{
${ }^{17}$ Note though that Broome (2005) does not in fact deny that there are reasons to comply with $\mathrm{WS}_{\mathrm{RR}}$. He is agnostic. The point is that formulating the principle in terms of rationality means that its fate is not contingent on there being such reasons.

${ }^{18}$ For the example, see Williams 1981. For appeal to it or similar examples in motivating a distinction between reasons and rationality see Broome 2007; Parfit 2001; Schroeder 2007, forthcoming; Setiya 2007a, 2007b; Wedgwood 2003. For skepticism about the distinction, see Dancy 2000: chap. 3; Kolodny 2005, esp. 555-6.
} 
In outline, I accept this picture. Rationality and reasons can indeed come apart in these ways - rational requirements are not just wide-scope oughts. So I do not take it to be an objection to $\mathrm{WS}_{\mathrm{RR}}$ that there may not be reasons to comply with it in every case. But acknowledging this is not enough to solve the Normativity Problem. The problem arises if there are any cases in which there is a reason to comply with $\mathrm{WS}_{\mathrm{RR}}$ but it is unclear what this reason is. And the view that rational requirements are wide-scope oughts is not the only view of the relation between reasons and rationality which entails that there are such cases. In what follows I sketch a much weaker - and I think attractive - view of this relation which also has this consequence. Broome's move is thus not sufficient to evade the Normativity Problem. It also requires rejecting this attractive view.

The sort of view I have in mind can be motivated by reconsidering Williams' case. Why is it rational to intend to take a sip from the glass? The following points seem pertinent. First, you believe that there is gin and tonic in the glass. Second, things are otherwise such that if there was gin and tonic in the glass, there would be good enough reason to intend to take a sip. That is, it seems to be part of the explanation of the rationality of this intention that it is formed in response to a consideration which, if true, would be sufficient reason for it.

So this kind of case suggests that the rationality of an attitude turns on the propositions you believe which, if true, would be (object-given) reasons for and against it. (The reasons must be object-given since, as noted above, it does not seem irrational to fail to respond to state-given reasons). Following Derek Parfit (2001), we can call such propositions apparent reasons. ${ }^{19}$ On this kind of view, the rationality of an attitude turns on the weight of the apparent reasons for and against it. An attitude or pattern of attitudes

${ }^{19}$ Or better, 'apparent object-given reasons'. In this section I will take this qualification as given. 
is rational if supported by adequate apparent reasons, and rationally required if supported by conclusive apparent reasons. ${ }^{20}$ This kind of view has two principal attractions. First, it allows us to preserve something of the intuitively compelling idea that rationality is a matter of responding correctly to reasons. Rationality is a matter of responding correctly to apparent reasons - considerations which would be reasons if true. Second, it allows us to explain rational requirements in terms of reasons. The view thus answers the question of just how reasons and rationality are related, if the latter is not just a special case of the former.

If something like this view is correct, the retreat to $\mathrm{WS}_{\mathrm{RR}}$ only puts off the Normativity Problem. The view understands rationality in terms of apparent reasons, which are considerations which are reasons if true. So if, as $\mathrm{WS}_{\mathrm{RR}}$ says, you are rationally required to be means-end coherent, you must believe things which, if true, would be reasons to be means-end coherent. Furthermore this kind of view makes it very plausible that in certain ideal circumstances what you are rationally required to do will coincide with what you ought to do. In particular, it makes it plausible that in circumstances in which you have only true beliefs and all relevant non-normative information, you will be rationally required to do something only if you ought to do it. ${ }^{21}$ If so, you will have conclusive reason to comply with $\mathrm{WS}_{\mathrm{RR}}$ when you have complete non-normative information and no false belief. But we still do not know what this reason is. ${ }^{22}$

\footnotetext{
${ }^{20}$ These formulations are closer to those in Schroeder forthcoming than Parfit 2001. They thereby avoid problems for Parfit due to Jacob Ross and discussed in Schroeder forthcoming. Thanks to an anonymous referee for suggesting I take account of these issues.

${ }^{21}$ Cf. Schroeder's 'very weak ought test' in forthcoming, sec. 2.2

${ }^{22}$ A parallel point is made in Setiya 2007b. Setiya notes that $\mathrm{WS}_{\mathrm{RR}}$ avoids the Transmission Problem (see below) only if we also give up the kind of view of rationality sketched here. See also Schroeder forthcoming, 2.2.
} 
As I have said, I take the conception of rationality sketched here to be attractive. It would be very puzzling if rational decision had nothing essential to do with what there is reason to do, even in ideal epistemic conditions. However it would take at least another paper to develop and defend this view. Instead I shall argue that attachment to the WideScope approach does not require us to give it up. There is a Wide-Scope account of the instrumental principle which preserves these connections between reasons and rationality but answers the Normativity Problem. I will explain by returning to our motivating example.

You intend to ride the rollercoaster and believe that standing in line is necessary for doing so. Suppose that this belief constitutes knowledge. It is then very plausible that you should either give up the intention to ride or else intend to stand in line. If we ask why you should - that is, if we ask for a reason - the answer that immediately presents itself is simply that standing in line is necessary for riding. I suggest that we take this answer at face value. The reason to [intend to stand in line, if you intend to ride] is simply that standing in line is necessary for riding. This fact is, as I shall put it, a Wide-Scope reason - a reason against a particular combination of attitudes. More generally, I suggest the following:

(WSR $)_{1} \quad$ The fact that doing $\mathrm{M}$ is necessary for doing $\mathrm{E}$ is a conclusive reason to [intend to do $\mathrm{M}$, if you intend to do $\mathrm{E}] .^{23}$

$\mathrm{WSR}_{1}$ preserves the guiding idea of the Wide-Scope approach - that the instrumental principle is a constraint on a combination of attitudes - and has just the

\footnotetext{
${ }^{23}$ A claim very close to this is suggested, but not defended, in Setiya 2007b: 661-2.
} 
advantages over Narrow-Scope views that WS does. But it gives us a straightforward solution to the Normativity Problem - the reason to [intend to do $\mathrm{M}$, if you intend to do $\mathrm{E}]$ is just that doing $\mathrm{M}$ is necessary for doing $\mathrm{E} .^{24}$

Unlike the Wide-Scope principles WS and $\mathrm{WS}_{\mathrm{RR}}$, $\mathrm{WSR}_{1}$ does not purport to give a fully general account of instrumental reason. Whereas those principles applied in all cases, $\mathrm{WSR}_{1}$ applies only in cases in which it is a fact that doing $\mathrm{M}$ is necessary for doing E. It says nothing about cases in which you falsely believe that doing $\mathrm{M}$ is necessary for doing E. However if we accept that reasons and rationality are connected in the way sketched above, we get a more general account. Whether or not an attitude or pattern of attitudes is rational depends on the weight of the apparent reasons for and against it. $\mathrm{WSR}_{1}$ tells us that the fact that doing $\mathrm{M}$ is necessary for doing $\mathrm{E}$ is a conclusive reason to [intend to do $\mathrm{M}$, if you intend to do E]. So if you believe that doing $\mathrm{M}$ is necessary for doing $\mathrm{E}$ then, if your belief is true, you have reason to [intend to do $\mathrm{M}$, if you intend to do E]. So you have an apparent reason to [intend to do M, if you intend to do E]. Furthermore it is plausible that this apparent reason will typically be conclusive, as the reason it is explained by is conclusive. If so:

$\left(\mathrm{WSR}_{2}\right) \quad$ If you believe that doing $\mathrm{M}$ is necessary for doing $\mathrm{E}$, you are rationally required to [intend to do $\mathrm{M}$, if you intend to do $\mathrm{E}] .^{25}$

\footnotetext{
${ }^{24}$ It is generally accepted that reasons are facts, and that a fact (that $p$ ) can be a reason for an agent even if that agent does not believe that $p$. However it might be insisted that the relevant facts do have to bear some kind of epistemic relation to the agent for whom they are reasons. Perhaps they have to pass through an 'epistemic filter' (Dancy 2000: 57-9, 65-6). If this is right the antecedent of WSR W $_{1}$ will need to be modified to take account of it. For present purposes we can stick with the simpler formulation.

${ }^{25}$ More needs to be said about the weight of apparent reasons to establish that $\mathrm{WSR}_{2}$ follows from $\mathrm{WSR}_{1}$. But a sketch of an argument can be provided. It is a familiar idea that you ought to do A if you have reason to do A and no reason not to do A. By analogy, it is plausible that you are rationally required to do A if you have apparent object-given reason to do A and no apparent object-given reason not to do A. Now when you
} 
$\mathrm{WSR}_{2}$ tells us that it is irrational to fail to intend what you take to be the necessary means to your intended ends. It is violated in every case in which $\mathrm{WS}_{\mathrm{RR}}$ is violated. ${ }^{26}$ The conjunction of $\mathrm{WSR}_{1}$ and $\mathrm{WSR}_{2}$ I call the Wide-Scope Reasons view.

There is a potential lacuna in this account. As I have emphasized, rationality requires responding only to apparent object-given reasons. So $\mathrm{WSR}_{2}$ follows from $\mathrm{WSR}_{1}$ only if the fact that doing $\mathrm{M}$ is necessary for doing $\mathrm{E}$ is an object-given reason to [intend to do $\mathrm{M}$, if you intend to do E]. But it is plausible that it is. I consider this point in a little more detail below, but for now we can make three points. First, it is a fact about the relationship between doing $\mathrm{M}$ and doing $\mathrm{E}$, not about the intentions to do $\mathrm{E}$ and to do $\mathrm{M}$. It does not involve any properties of these intentions, and so it is hard to see how it could be a state-given reason. Second, it is not a reason in virtue of the benefits of [intending to do $\mathrm{M}$, if you intend to do E], in the way that state-given reasons typically are. This must be so if we agree with Kolodny that the reason to comply cannot be purely instrumental. Third, it seems to be the kind of consideration you can directly respond to, in the way characteristic of object-given reasons. If you intend to ride the rollercoaster and know that standing in line is necessary for doing so, you are thereby in a position to either form

believe that doing $\mathrm{M}$ is necessary for doing $\mathrm{E}$ you have apparent object-given reason to [intend to do $\mathrm{M}$, if you intend to do E]. Thus you will be rationally required to [intend to do $\mathrm{M}$, if you intend to do E] unless you also have apparent object-given reason not to [intend to do M, if you intend to do E]. But it is very hard to see what could be an object-given reason not to [intend to do M, if you intend to do E]. (As we shall see in section 5, it is not hard to see what a state-given reason might be). On the conjecture that there are no

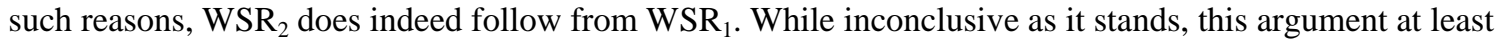
lays down a challenge: what might be an object-given reason not to [intend to do $\mathrm{M}$, if you intend to do E]? I develop this line of thought in work in progress. I thank John Broome, Mark Schroeder and an anonymous referee for pressing me on this point.

${ }^{26}$ However there are cases in which you comply with $\mathrm{WS}_{\mathrm{RR}}$ but not with $\mathrm{WSR}_{2}$. If you do not believe that doing $\mathrm{M}$ is necessary for doing $\mathrm{E}$ then you comply with $\mathrm{WS}_{\mathrm{RR}}$ but you neither comply with nor violate $\mathrm{WSR}_{2}$. WSR $\mathrm{Wimply}_{2}$ does not require anything of you in that case. There is a possible advantage to $\mathrm{WSR}_{2}$ here, as some find it is implausible that you can come to comply with the instrumental principle by giving up a belief (Schroeder 2004: 346). 
the intention to join the line or else give up the intention to ride. In this respect it is like the object-given reasons to intend to ride the rollercoaster - such as that riding would be exhilarating - and unlike state-given reasons, such as the reason to intend to drink the toxin.

In this section I have developed a version of the Wide-Scope view which answers the Normativity Problem without giving up what I take to be an intuitive connection between reasons and rationality. It is a central claim of this view that the reason to [intend to do $\mathrm{M}$, if you intend to do $\mathrm{E}$ ] is object-given, not state-given. Although we lack a precise way of drawing this distinction, $\mathrm{WSR}_{1}$ has enough in common with paradigm object-given reasons to make it plausible that, if true at all, $\mathrm{WSR}_{1}$ is true as a claim about object-given reasons. In the next two sections I argue that this claim is also the key to answering two other important objections to Wide-Scope accounts.

\section{The Transmission Problem}

The Transmission Problem turns on the familiar fact that practical reasons transmit from ends to means. For example, if you have a reason to exercise, you have a reason to jog, as this is a way of exercising; if I have a reason to be in England, I have a reason to take a plane, as this will get me to England. More generally, the following means-end transmission principle seems plausible: 

you have a reason to do $\mathrm{B} .^{27}$

WSR $_{1}$ says that when doing $\mathrm{M}$ is necessary for doing $\mathrm{E}$ you have conclusive reason to [intend to do M, if you intend to do E]. One way to comply with this reason - and thus a sufficient means to doing so - is to intend to do M. Another way is not to intend to do E. So given $T_{1}$, WSR 1 seems to imply that if doing $M$ is a necessary means to doing $E$, you have a reason to intend to do $\mathrm{M}$, and a reason not to intend to do $\mathrm{E} .^{28}$ This implication holds even if you do not intend to do E. It depends only on your having a reason to [intend to do $\mathrm{M}$, if you intend to do $\mathrm{E}$ ], and you have such a reason, $\mathrm{WSR}_{1}$ claims, whether or not you intend to do E.

$\mathrm{WSR}_{1}$ thus appears to have the surprising consequence that for any action which is a necessary means to some end, you have a reason to intend that action. ${ }^{29}$ If hiring an assassin is necessary for killing the president, you have a reason to intend to hire an assassin, whether or not you intend to kill the president; if taking all your green books off the shelf is necessary for putting them on the roof, you have a reason to intend to take all your green books off the shelf, whether or not you intend to put them on the roof. It seems unlikely that reasons are so easy to come by. ${ }^{30}$

\footnotetext{
${ }^{27}$ A means is sufficient when it constitutes or causes an end. In the examples in the text, jogging constitutes exercise, taking a plane causes being in England. Not all means are sufficient in this sense. For example, breaking eggs is only a part of making an omelette, buying a ticket merely facilitates going to the show. Transmission principles hold for insufficient means too, but their formulation poses problems. The simpler case of sufficient means is all that the Transmission Problem needs.

${ }^{28}$ Raz (2005: 12) argues for this conclusion along similar lines. However it is unclear that Raz's argument is precisely the one presented here.

${ }^{29}$ Note that WS has even more generous consequences as it does not require the restriction to actions which are necessary for some end.

${ }^{30}$ Schroeder (2007: 92-97) argues that an assertion that there is reason to do A is ordinarily conversationally appropriate only when there is significant or weighty reason to do A. Thus an assertion
} 
As Setiya has argued, this objection can be strengthened (Setiya 2007b. See also Greenspan 1970, Schroeder forthcoming). If there are multiple means to an end, the reason for each need not be as strong as the reason for the end. The strength of the reason for any particular means will depend on how good it is as a means, and on the other reasons for and against it. However if a means is necessary for an end, the reason in favor of it must be at least as strong as the reason for the end. This gives us a second means-end transmission principle (Schroeder forthcoming):

If you have a reason to do A and doing B is a necessary means to doing A, you have a reason to do B which is at least as strong as your reason to do A.

Now suppose that intending to do $\mathrm{M}$ is necessary for [intending to do $\mathrm{M}$, if you intend to do E]. For example, suppose that you intend to smoke but are psychologically incapable of giving up this intention. (This may seem strange, but seems at least possible). ${ }^{31}$ And suppose that buying cigarettes is necessary for smoking. $\mathrm{WSR}_{1}$ tells us that you therefore have conclusive reason to [intend to buy cigarettes, if you intend to smoke]. And given that you are unable to comply with this reason by giving up the intention to smoke, $\mathrm{T}_{2}$ seems to imply that there is conclusive reason to intend to buy cigarettes.

\footnotetext{
that there is reason to do A is liable to sound false if there is only weak reason to do A. This observation may go some way towards meeting the objection. But concerns remain. For we might well wonder what could make it true that whenever doing $\mathrm{M}$ is necessary for doing $\mathrm{E}$, you have a reason to intend to do $\mathrm{M}$ (and a reason not to intend to do E). The means-end fact alone simply does not look substantial enough to explain such reasons. If there is no reason to do $\mathrm{E}$, why should there be any reason to intend to do $\mathrm{M}$ ?

${ }^{31}$ If you are not convinced, consider a case in which a Frankfurt-style intervener wants you to intend to smoke and has the technology to ensure that you have this intention, but will intervene only if he thinks that you are going to give up this intention. Cf. Frankfurt 1988.
} 
The Wide-Scope approach thus seems susceptible to a version of the initial

problem for the Narrow-Scope view. $\mathrm{NS}_{1}$ claimed that if you intend to do E, you ought to

intend the believed necessary means to doing E. This was shown to be false by counter-

example. It might be that you intend to smoke but ought not intend to buy cigarettes - for

example, if you ought not to be smoking. The problem here is parallel. It might be that

you intend to smoke, cannot give up that intention, but ought not intend to buy cigarettes

- for example, if you ought not to be smoking. If the Wide-Scope approach implies

otherwise, the Wide-Scope approach fails. ${ }^{32}$

\section{Answering the Transmission Problem}

To answer the Transmission Problem we need a principled way to deny that the means-

end transmission principles $\mathrm{T}_{1}$ and $\mathrm{T}_{2}$ can be applied to $\mathrm{WSR}_{1}$. It is here, I will argue, that

\footnotetext{
${ }^{32}$ I will note two replies I think unsuccessful. First, John Broome has suggested to me that $T_{2}$ is shown to be false by the following kind of example. You ought to see the doctor and taking the day off work is necessary for doing so. However if you took the day off work you would sit around watching TV and would not see the doctor. Thus you ought not take the day off work even though it is necessary for doing something you ought to do. However such examples do not threaten the following modified principle, which leads to just the same problem for the Wide-Scope approach:
}

$\left(\mathrm{T}_{2}{ }^{*}\right)$ If you have a reason to do A and doing B is both a necessary and sufficient means to doing A, you have a reason to do B which is at least as strong as your reason to do A.

In Broome's example, taking a day off work is not sufficient for seeing the doctor. However in Setiya's example, intending to buy cigarettes is both necessary and sufficient for [intending to buy cigarettes, if you intend to smoke]. For brevity, I will continue to work with the unmodified $\mathrm{T}_{2}$. The examples I discuss can easily be modified so as to bear on $\mathrm{T}_{2}$ *.

Second, an anonymous referee has suggested to me that the problem depends on the contentious principle that you have reason to do A only if you are psychologically capable of doing A. However this dependence is indirect at best. All that you are psychologically incapable of doing is giving up the intention to smoke. But the objection does not assume that you do not have reason to give up this intention. It simply applies the transmission principle $T_{2}$ to the Wide-Scope claim that you have conclusive reason to [intend to buy cigarettes, if you intend to smoke]. For sure, if you do have conclusive reason to give up the intention to smoke, despite the inability to do so, it is even harder to see how you could have conclusive reason to intend to buy cigarettes. But that is a problem for the Wide-Scope view, not the objection. On the other hand, it may be that the rationale for the transmission principle depends on a version of 'ought' implies 'can'. If so, and if this fails for psychological capacity, this may provide a deeper rationale for the argument below that means-end transmission principles cannot in general be applied to reasons for attitudes. 
attention to the distinction between object- and state-given reasons is important. The transmission principles seem compelling if we understand them solely as claims about reasons for action. But if we take them also to apply to reasons for attitudes, things are more complicated. I will argue that although state-given reasons transmit from ends to means, object-given reasons do not. So if $\mathrm{WSR}_{1}$ is a claim about object-given reasons, the problem is avoided.

It will be useful to begin by clarifying what the transmission principles say when applied to reasons for attitudes. Taken together, the principles say that when there is a reason for an attitude (or combinations of attitudes), there is also reason for attitudes which are necessary or sufficient means to that attitude (or combination of attitudes). This raises the question of what it is for an attitude to be a means to another. I will say that an attitude B is a sufficient means to an attitude A when having B will cause or constitute having A. And I will say that B is a necessary means to A if you are unable to have A unless you also have B. Similar remarks apply to reasons for combinations of attitudes. So the question to address is whether reasons transmit across these connections between attitudes. For simplicity, I will initially take as examples cases in which one attitude is a sufficient means to another, but nothing essential turns on this.

State-given reasons do conform to the transmission principles. There is stategiven reason for an attitude A when there are properties of that attitude which make it in some way good to have. Suppose A has such properties. Then if some further attitude B will cause you to have A, B has properties which make it in some way good to have. B is such that it will cause you to have A, which it would be good to have. That is a benefit of having B. So means-end transmission holds for state-given reasons: 
$\left(\mathrm{T}_{3}\right) \quad$ If you have a state-given reason for attitude A and attitude B is a necessary or sufficient means to attitude A, you have a state-given reason for attitude B.

Examples confirm the point. Suppose it would make Sam happy to believe that she deserves an A on her biology final. And suppose Sam will believe this if she also believes that her teacher made a mistake. Then insofar as there are benefits to having the former belief, there are also benefits to having the latter belief. The state-given reason to believe that she deserves an A transmits a state-given reason to believe that her teacher made a mistake. Or suppose that the belief that you ought to drink the toxin will lead you to intend to drink the toxin. Then as there are benefits to intending to drink the toxin, there are also benefits to believing that you ought to drink the toxin. The state-given reason to intend to drink transmits to a state-given reason to believe that you ought to drink.

Object-given reasons are different. There is no guarantee that there will be objectgiven reason for an attitude B just because it will cause you to have an attitude for which there is object-given reason. This is perhaps clearest if we consider epistemic reasons, which are object-given reasons for belief. Suppose that Sam will accept that humans descended from apes if she also accepts that this is part of God's plan for the world. For Sam, the latter belief is a means to the former. Yet she could easily have epistemic reason to think that humans descended from apes without having epistemic reason to think that this is part of a divine plan. ${ }^{33}$

\footnotetext{
${ }^{33}$ Setiya (2007b) appeals to this point about epistemic reasons in motivating his 'cognitivism about instrumental reason'. Setiya argues that we should understand the demands of instrumental reason as demands of epistemic reason, on the grounds that epistemic reasons do not transmit along means-end lines. My claim is that this fact about epistemic reasons is just an instance of a more general point about object-
} 
The point does not depend on the fact that such reasons are epistemic, rather than practical. Analogous points can be made about object-given reasons for desire. Objectgiven reasons for desire turn on the desirability of their object. But a desire that $p$ can lead to a desire that $q$, although it is desirable that $q$ but not that $p$. For example, a desire to repeatedly wash your hands might cause a desire to seek psychological help. The desire to repeatedly wash your hands is thus a means to the desire to seek help. But this hardly shows that seeking help is desirable only if repeatedly washing one's hands is. Object-given reasons for desire do not transmit along means-end lines. ${ }^{34}$

Now consider reasons for intention, which for our purposes are the crucial case. There is object-given reason to intend to do A only if there is reason to do A. But the fact that an intention to do B is a means to an intention to do A does not ensure that there is reason to do B if there is reason to do A. Means-end connections between intentions need not mirror means-end connections between actions: intending to do B may be a means to intending to do A although doing B is not a means to doing A. In such cases there can be object-given reason to intend to do A but not object-given reason to intend to do B.

Consider an example, this time of a necessary means. Harry has reason to give money to charity; he can afford it and the money would do a lot of good. He therefore has object-given reason to intend to give money. However Harry is psychologically incapable of intending to give the money unless he also intends to tell all his colleagues about it. So intending to tell is a necessary means to intending to give. It does not follow, though, that

given reasons, and thus that we can avoid the problem without cognitivism. For discussion of cognitivism see Bratman forthcoming $a$ and $b$.

${ }^{34}$ Note though that there is another sense in which we might say that reasons for desire do transmit along means-end lines. If it is desirable that $p$, and $q$ is a means to $p$, then to that extent $q$ must also be desirable so there will be object-given reason to desire that $q$. The difference between this principle and the principle considered in the text is that in this case the means is to a state of affairs or action - the object of a desire and not to the desire itself. Nothing I say here casts doubt on this very different principle. 
Harry has object-given reason to intend to tell. Harry has an object-given reason to intend to tell only if he has a reason to tell, but he need not have such a reason. For although intending to tell is necessary for intending to give, telling need not itself be necessary for giving. Suppose, for instance, that the opportunity to give comes before the opportunity to tell. Then the reason to give will not transmit to a reason to tell, and there may be no other reason to tell - perhaps telling his colleagues will only irritate them. In such a case Harry will have object-given reason to intend to give but no object-given reason to intend to tell, although intending to tell is necessary for intending to give. ${ }^{35}$ Object-given reasons for intention do not transmit from ends to means. ${ }^{36}$

As we have seen, this is an example of the more general point that object-given reasons for attitudes do not transmit from ends to means. The following principles are false:

$\left(\mathrm{T}_{4}\right) \quad$ If you have an object-given reason for attitude A and attitude B is a sufficient means to attitude A, you have an object-given reason for attitude B.

( $\mathrm{T}_{5}$ ) If you have an object-given reason for attitude A and attitude B is a necessary means to attitude A, you have an object-given reason for attitude B.

\footnotetext{
${ }^{35}$ Harry may have state-given reason to intend to tell. This intention is plausibly a means to giving to charity, and so would have beneficial consequences. The crucial point is that this reason is not object-given - it derives from benefits of intending to tell which are unrelated to whether he ends up telling.

${ }^{36}$ As with reasons for desire, we can acknowledge another sense in which object-given reasons for intention transmit along means-end lines. If there is object-given reason to intend to do A and doing $\mathrm{B}$ is a means to doing $\mathrm{A}$, then there will be object-given reason to intend to do $\mathrm{B}$. But in this case the means is to doing A, not to intending to do A. Nothing I say here casts doubt on this principle either.
} 
But if so, and if $\mathrm{WSR}_{1}$ is a claim about object-given reasons, there is a principled way to avoid the Transmission Problem. The problem turns on applying means-end transmission principles to $\mathrm{WSR}_{1}$. But if $\mathrm{WSR}_{1}$ is a claim about object-given reasons, the required transmission principles are false - as the example of Harry shows, object-given reasons for intention do not transmit along means-end lines. It is only if $\mathrm{WSR}_{1}$ is a claim about state-given reasons that the problem arises. ${ }^{37}$

\section{The Evil Demon Problem}

I now turn to the third objection. The Wide-Scope claim that there is conclusive reason to [intend to do M, if you intend to do E] seems to be equivalent to the claim that you ought to [intend to do M, if you intend to do E]. However we can describe situations in which it seems that you ought not [intend to do M, if you intend to do E]. For example, suppose that an evil demon threatens to kill you unless you both intend to do E and do not intend to do M. Here the demon's threat seems to make it the case that you ought not [intend to do M, if you intend to do E]. But it is difficult to see how it could be the case both that you ought to [intend to do M, if you intend to do E], and that you ought not. And as

\footnotetext{
${ }^{37}$ We might wonder whether there is a way to rehabilitate the objection. I noted (n. 35) that Harry may have state-given reason to intend to tell his colleagues about his donations, as this intention is a necessary means to giving the money. It might be wondered whether it does not also follow from the fact that there is object-given reason to [intend to buy cigarettes, if you intend to smoke] that there is state-given reason to intend to buy cigarettes, in Setiya's case, as this is a necessary means to complying with this reason.

This would follow if wherever there is object-given reason for attitude A, and attitude B is a means to attitude A, there is state-given reason for attitude B. But it is not clear why we should accept this. Harry's case does not motivate it. In Harry's case the state-given reason to intend to tell does not derive from the fact that this intention is a means to intending to give. It turns on the fact that intending to tell is a means to giving. In the smoking example, by contrast, intending to buy cigarettes is not a means to performing any action that there is reason to perform. Another possible motivation would be the thought that wherever there is object-given reason for attitude A, there is also state-given reason for attitude A. But this is also questionable. It is not always good or beneficial to have attitudes which are supported by objectgiven reasons. (cf. Danielsson and Olson 2007: 515, 519)
} 
saving your life seems far more important than the means-end coherence of your intentions, $\mathrm{WSR}_{1}$ seems to be subject to counter-example (Reisner unpublished. See also Broome 2005: 324-5, Feldman 1986: 124).

This argument calls for greater care in the statement of $\mathrm{WSR}_{1}$. An initially tempting move is to retreat to the claim that there is merely some reason - not necessarily conclusive - to [intend to do M, if you intend to do E]. However this response would not account for the strictness of instrumental reason. It would not explain why means-end incoherence is irrational. Strictness was the original motivation for the claim of conclusiveness in $\mathrm{WSR}_{1}$.

However strictness does not require the Wide-Scope reason to be, as I shall put it, conclusive simpliciter. It does not need to be conclusive out of all the reasons, both object- and state-given. As we have seen, rationality does not require conformity to apparent state-given reasons. It requires conformity only to apparent object-given reasons. So we explain strictness as long as the Wide-Scope reason is conclusive out of the object-given reasons. It does not need to be conclusive out of both the object- and state-given reasons. I thus recommend that we understand $\mathrm{WSR}_{1}$ as the claim that the fact that doing $\mathrm{M}$ is necessary for doing $\mathrm{E}$ is a reason to [intend to do $\mathrm{M}$, if you intend to do E] which is conclusive out of the object-given reasons - for short, a conclusive objectgiven reason.

So understood, $\mathrm{WSR}_{1}$ is not threatened by the evil demon case. The demon's threat provides only a state-given reason - that intending to do E but not intending to do M will save your life. So this is a case in which there is conclusive object-given to [intend to do M, if you intend to do E] and conclusive state-given reason not to. (We can 
stipulate that the threat provides your strongest state-given reason). But this is perfectly intelligible. It just means that the object-given reasons come down in favor of one response and the state-given reasons come down against that response. Arguably, the same thing happens in the toxin puzzle: the unpleasantness of the toxin provides conclusive object-given reason against intending to drink, but the benefits of so intending provide conclusive state-given reason to intend to drink.

What ought you to do in these situations? Strictly speaking, I need not take a stand on this question. The attitudes you ought to have are those for which there is conclusive reason simpliciter- that is, conclusive not merely out of the object- or stategiven reasons but out of all the reasons. Thus whether you ought to intend to drink the toxin, or ought not [intend to do M, if you intend to do E], depends on whether the stategiven reasons in these cases are weightier than the object-given reasons - a point on which I can be neutral. However I will register my intuition that in both these cases the state-given reasons outweigh the object-given reasons. ${ }^{38}$ If that is right then you ought to intend to drink the toxin and you ought not [intend to do M, if you intend to do E], as the objection suggested. But that is not incompatible with your having conclusive objectgiven reason to [intend to do $\mathrm{M}$, if you intend to do E]. It is therefore no counter-example to $\mathrm{WSR}_{1}$, as we are now understanding it.

\section{Is the Reason Really Object-Given?}

I have explained how the Wide-Scope Reasons view proposes to answer three important objections to the Wide-Scope approach. It has been a crucial claim that the reason to

\footnotetext{
${ }^{38}$ For discussion of how object- and state-given reasons may be weighed, see Reisner 2008.
} 
comply with $\mathrm{WSR}_{1}$ is an object-given reason. In this section I consider an objection to this claim, which arises from a point of disanalogy between $\mathrm{WSR}_{1}$ and paradigmatic object-given reasons.

In paradigm cases, object-given reasons to intend to do A derive from reasons to do A, and object-given reasons against intending to do A derive from reasons not to do A. For example, the fact that it is a nice day out is a reason to take a walk, and so a reason to intend to take a walk. The fact that you have a stack of grading due tomorrow is a reason not to take a walk, and so not to intend to take a walk. This connection between reasons for action and intention holds for some putative wide-scope reasons too. Consider Jonathan Dancy’s suggestion that reasons against hypocrisy are reasons against a combination of actions - approximately, against telling others that some action ought to be done while not doing it oneself..$^{39}$ If this suggestion is right then there is also a reason not to hold hypocritical intentions - not to [intend to tell others that they ought to do A while not intending to do A oneself]. This would be a wide-scope reason and it would clearly be object-given, since it derives from a reason against a combination of actions.

These examples may suggest that object-given reasons for intentions always derive from reasons to act. On that assumption, an object-given reason to [intend to do $\mathrm{M}$, if you intend to do E] must derive from a reason to [do M, if you do E]. This presents a potential problem for the Wide-Scoper, since it is not clear that there are reasons to [do $\mathrm{M}$, if you do E], in the conditions in which $\mathrm{WSR}_{1}$ applies. When doing $\mathrm{M}$ is a necessary means to doing E, you cannot do E unless you also do M, and so cannot fail to [do M, if you do E]. But many philosophers hold that if it is not possible to fail to do something,

\footnotetext{
${ }^{39}$ Dancy 2000: 54. Dancy's example is of believing that an action is wrong but doing it oneself, but I take it that his point has wider application. Of course, various qualifications would be needed before these descriptions amounted to a plausible characterization of hypocrisy. But the basic idea is all we need here.
} 
there can be no reason to do that thing. These philosophers accept an violation constraint on practical reasons: there is reason to do A only if it is possible not to do A. ${ }^{40}$ This constraint entails that when doing $\mathrm{M}$ is necessary for doing $\mathrm{E}$, there is no reason to [do M, if you do E]. So if object-given reasons for intention must derive from reasons to act, there is no object-given reason to [intend to do $\mathrm{M}$, if you intend to do E] either.

I cannot here address the plausibility of the violation constraint. Instead, I will argue that accepting it does not preclude thinking that there is object-given reason to [intend to do M, if you intend to do E]. At least if we accept the violation constraint, we should deny that all object-given reasons for intention derive from reasons for action. We should think that object-given reasons for intention can also derive from other properties of an intended action.

Consider some action you are unable to perform - for example, seeing the show that starts in an hour's time one thousand miles away. If we grant the violation constraint, there is no reason not to see the show, as seeing the show is not something you can do. However it is not impossible to intend to see the show, so the violation constraint does not rule out reasons not to intend to see the show. And as you cannot see the show, it is plausible that there is strong reason not to intend to see the show. Because you cannot see the show, intending to do so is a mistake. As such it is plausible that the reason against intending to see the show is just the fact that you cannot see it.

It is further plausible that this reason is object-given, for two reasons. First, the fact that you cannot see the show is a fact about seeing the show, not the intention to do so. Second, it seems clearly irrational to intend to see the show if you believe that you

\footnotetext{
${ }^{40}$ For a recently influential example see Korsgaard 1997. For discussion and further references see Lavin 2004.
} 
cannot do so. And we are assuming that rationality is to be understood in terms of apparent object-given reasons. So if it is irrational to intend to see the show you must believe something which, if true, would be an object-given reason against intending to see it. The best candidate to be this reason is the fact that you cannot see the show.

So it is plausible that the fact that you cannot see the show is an object-given reason not to intend to see it. But we are also assuming, by the violation constraint, that there is no reason not to see the show. So we must allow that there can be an object-given reason not to intend to see the show even though there is no reason not to see the show. So not all object-given reasons bearing on intentions derive from reasons to act.

It may be objected that the fact that you cannot see the show is only a reason not to intend to see it because this intention will have bad consequences. For example, it may lead you to waste time and resources taking ineffective means trying to see it. If so, then the reason would be state-given, after all. But such considerations seem not to tell the whole story. Suppose an eccentric billionaire offers a large prize for intending to see the show. If the prize is large enough it may outweigh other possible bad consequences of intending to see it, so that intending to see the show is better for you, overall, than not intending to see it. If there are only state-given reasons in this case, we should expect there to be no remaining sense in which you should not decide to go. Making this decision is the right decision, if we judge only by the costs and benefits of intending to go.

I submit that even in this case there remains a sense in which you should not intend to see the show. There is a partial analogy here with the toxin puzzle. In that case there remains a sense in which you should not intend to drink the toxin, despite the 
benefits of doing so. Intending to drink the toxin is irrational, as it is an intention to do something you know you should not do. I suggest that intending to see the show is also irrational, as it is an intention to do something you know you cannot do.

So at least if we assume the violation constraint, we need to recognize objectgiven reasons against intention which do not derive from reasons against the action intended. The fact that object-given reasons for intention typically derive from reasons for or against action does not show that $\mathrm{WSR}_{1}$ cannot be a claim about object-given reasons. That doing $\mathrm{M}$ is necessary for doing $\mathrm{E}$ can be an object-given reason to [intend to do $\mathrm{M}$, if you intend to do $\mathrm{E}$ ] even if it is not also a reason to [do $\mathrm{M}$, if you do $\mathrm{E}$ ].

\section{Conclusion}

In this paper I have considered three objections to the Wide-Scope approach: the Normativity Problem, the Transmission Problem and the Evil Demon Problem. Each problem turns on the Wide-Scoper's claim that, at least in a significant range of cases, you have conclusive reason to comply with the Wide-Scope instrumental principle. And I have argued for a view, the Wide-Scope Reasons view, which answers these objections without giving up on this claim. There is therefore no need to deny that there are important connections between reasons and rationality, such that in many cases there is conclusive reason to do what you are rationally required to do. And this is a good thing, since I take such connections both to be intuitive and to allow for explanatory work.

Of course further objections remain. Not all objections to the Wide-Scope approach turn on the Wide-Scoper's claim about reasons. For instance, some object to the 
symmetry the Wide-Scope view sees between intending the means to your end and giving up that end. ${ }^{41}$ And certainly much more needs to be done to vindicate the framework for thinking about reasons and rationality that the Wide-Scope Reasons view is embedded in. But this work will have to be done on another occasion. What I have argued here is that the Wide-Scope Reasons view is the most promising version of the Wide-Scope approach to instrumental reason. ${ }^{42}$

\section{References}

Audi, R. (2001). The Architecture of Reason. Oxford: Oxford University Press.

Bratman, M. (1987). Intentions, Plans and Practical Reason. Cambridge, Mass: Harvard University Press.

(forthcoming a). Intention, Belief, Theoretical, Practical. In J. Timmerman, J.

Skorupski and S. Robertson (Eds.), Spheres of Reason.

(forthcoming b). Intention, Belief and Instrumental Rationality. In D. Sobel and S. Wall (eds.), Reasons for Action.

Broome, J. (1999). Normative Requirements. Ratio 12 (4), 398-419.

(2001). Are Intentions Reasons? And How Should We Cope With

Incommensurable Values? In C. Morris and A. Ripstein (Eds.), Practical Rationality and

\footnotetext{
${ }^{41}$ Schroeder 2005: 9. And for related discussion see Schroeder 2004, Kolodny 2005: 527-8. Schroeder 2004 also raises other worries about the Wide-Scope approach not discussed here.

${ }^{42}$ I would like to thank John Broome, Errol Lord, Ian Nance, Simon Rippon, Mark Schroeder, Aaron Zimmerman, and an anonymous referee for Philosophical Studies, for extremely useful written comments and discussion, and Kevin Falvey, Matt Hanser, and Steve Sverdlik for especially helpful discussion. Versions of the paper were presented at the UCSB Philosophy Graduate Colloquium, the $11^{\text {th }}$ Southern California Philosophy Conference at CSU Northridge, the 2008 Pacific APA in Pasadena, the University of Stirling, and the 2008 British Society for Ethical Theory Conference at the University of Edinburgh. I am grateful to the audiences on these occasions for their comments and questions, and Alastair Norcross, my commentator in Pasadena, for his criticisms.
} 
Preference: Essays for David Gauthier (pp. 98-120). Cambridge: Cambridge University

Press.

(2002). Practical Reasoning. In J. Bermudez and A. Miller (Eds.), Reason and Nature: Essays in the Theory of Rationality (pp. 85-111). Oxford: Oxford University Press.

(2004). Reasons. In R. J. Wallace, M. Smith, S. Scheffler and P. Pettit (Eds.), Reason and Value: Themes from the Moral Philosophy of Joseph Raz (pp. 28-55). Oxford: Oxford University Press.

(2005). Does Rationality Give Us Reasons? Philosophical Issues 15 (Normativity), 321-37.

(2007). Does Rationality Consist in Responding Correctly to Reasons? Journal of Moral Philosophy. 4 (3), 349-74.

Dancy, J. (2000). Practical Reality. Oxford: Oxford University Press.

D’Arms, J. and Jacobsen, D. (2000). Sentiment and Value. Ethics 110 (4), 722-48.

Darwall, S. (1983). Impartial Reason. Ithaca: Cornell University Press.

(2001). Because I Want It. Social Philosophy and Policy 18 (2), 129-53.

Feldman, F. (1986). Doing the Best We Can. Dordrecht: D. Reidel Publishing.

Finlay, S. (forthcoming). Against All Reason? Skepticism about the Instrumental Norm. In C. Pigden (ed). Hume, Motivation and Virtue.

Frankfurt, H. (1988). Alternate Possibilities and Moral Responsibility. Reprinted in his The Importance of What We Care About (pp. 1-10). Cambridge University Press: Cambridge. 
Greenspan, P. (1970). Conditional Oughts and Hypothetical Imperatives. Journal of Philosophy 72 (10), 259-76.

Hieronymi, P. (2005). The Wrong Kind of Reason. Journal of Philosophy 102 (9), 43757.

Kavka, G. (1983). The Toxin Puzzle. Analysis 43 (1), 33-36.

Kolodny, N. (2005). Why Be Rational? Mind 114 (455), 509-63.

(2007). How Does Coherence Matter? Proceedings of the Aristotelian Society, 107 (1), 229-263.

(2008). Why be Disposed to be Coherent? Ethics. 118 (3), 437-63.

Korsgaard, C. (1997) The Normativity of Instrumental Reason. In G. Cullity and B. Gaut (Eds), Ethics and Practical Reason (pp. 215-254). Oxford: Oxford University Press.

Lavin, D. (2004) Practical Reason and the Possibility of Error. Ethics 114 (3), 424-57.

Olson, D and Danielsson, S. (2007). Brentano and the Buck-Passers. Mind 116 (463), $511-22$.

Parfit, D. (2001). Rationality and Reasons. In D. Egonsson, B. Petersson, J. Joselfsson, and T. Rønnow-Rasmussen, T (Eds.), Exploring Practical Philosophy: From Action to Values (pp. 17-39). Aldershot: Ashgate.

Pascal, B. (1996). Pensees, tr. A. J. Krailsheimer. New York: Penguin Press.

Pink, T. (1996). The Psychology of Freedom. Cambridge: Cambridge University Press.

Rabinowicz, W and Ronnow-Rasmussen, T. (2004). The Strike of the Demon: On Fitting Pro-Attitudes and Value, Ethics 114 (3), 391-423.

Raz, J. (2005). The Myth of Instrumental Rationality. Journal of Ethics and Social Philosophy 1, 2-28. 
Reisner, A. (2008). Weighing Pragmatic and Evidential Reasons for Belief. Philosophical Studies, 138 (1), 17-27.

(forthcoming). The Possibility of Pragmatic Reasons for Belief and the Wrong Kind of Reasons Problem.

(unpublished). Why Rational Requirements are not Normative Requirements.

Schroeder, M. (2004). The Scope of Instrumental Reason. Philosophical Perspectives 18 (Ethics), 337-64.

(2005). Instrumental Mythology. Journal of Ethics and Social Philosophy.

Symposium 1.

(2007). Slave of the Passions. Oxford: Oxford University Press.

(forthcoming). Means-End Coherence, Stringency, and Subjective Reasons, Philosophical Studies.

Setiya, K. (2007a). Reasons without Rationalism. Princeton University Press: Princeton. (2007b). Cognitivism About Instrumental Reason, Ethics 117 (4), 649-73.

Shah, N. (2006). A New Argument for Evidentialism. Philosophical Quarterly 56 (225), 481-98.

(2008). How Action Governs Intention. Philosophers' Imprint. 8 (5).

Stratton-Lake, P. (2005). How to Deal with Evil Demons. Ethics 115 (4), 788-98.

Wallace, R. J. (2001). Normativity, Commitment and Instrumental Reason. Philosophers' Imprint 1 (3).

Wedgwood, R. (2003). Choosing Rationally and Choosing Correctly. In S. Stroud and C. Tappolet (Eds.), Weakness of Will and Varieties of Practical Irrationality (pp. 201-29). Oxford: Oxford University Press. 
Williams, B. (1981). Internal and External Reasons. Reprinted in his Moral Luck (pp. 100-110). Cambridge: Cambridge University Press. 